\title{
RE-VISITED; ARE FOODS FRIEND OR FOE FOR CANCER?
}

\section{Taygun Dayi ${ }^{1}$, Adile Oniz Ozgoren ${ }^{2}$}

\author{
${ }^{1}$ Near East University, Faculty of Health Sciences, Department of Nutrition and Dietetics, Nicosia, Northern Cyprus \\ ${ }^{2}$ Near East University, Faculty of Health Sciences, Department of Health Management, Nicosia, Northern Cyprus \\ Address for Correspondence: Prof. Adile Oniz Ozgoren, E-mail: adile.oniz@neu.edu.tr \\ Received: 05.01.2021; Accepted: 28.01.2021; Available Online Date: 04.03.2021 \\ @C Copyright 2021 by Dokuz Eylül University, Institute of Health Sciences - Available online at https://dergipark.org.tr/en/pub/jbachs
}

Cite this article as: Dayi T, Oniz Ozgoren A. Re-Visited; are foods friend or foe for cancer? J Basic Clin Health Sci 2021; 1: $82-87$.

\begin{abstract}
Worldwide, the second most common disease which has high mortality range is cancer. Unhealthy lifestyle such as sedentary life, unbalanced nutrition habits etc. may increase cancer incidence. There is a bidirectional relation between foods and cancer. Some foods (red meat, processed meat products, salty foods, sugar, alcohol etc.) may cause to cancer and some of them such as fruits, vegetables, seeds, legumes, milk and dairy products, olive oil etc. may protect our body against cancer. In this mini- review; we aimed to re-assess effects of nutrition and some foods on cancer risk.
\end{abstract}

Keywords: Cancer, nutrition, foods etc.

Cancer is the second most common mortality cause worldwide (1). Cancer is believed to be triggered by smoking, alcohol consumption, sedentary lifestyle, some bacteria and viruses, ultra-violet rays and unhealthy/unbalanced nutrition habits (2). In this current mini-review; we aimed to re-examine effects of nutrition and some foods on cancer development risk.

There is an important relationship between nutrition and cancer risk. Some foods may decrease or increase the possibility of cancer (3) (Table 1).

Meat and meat products, fats, sugar, very hot and/or cold beverages, alcohol, salt and salty foods, foods which are contaminated by mold and bad cooking methods may increase some cancers risk. On the other hand; fresh vegetables and fruits, legumes, nuts and seeds, dairy products, fish, olive oil, prebiotics and probiotics may decrease this important risk (4).

\section{Potentially risky food}

Some potentially risky foods and their mechanisms are shown in Figure 1. The red meat contains high amount of heme-iron. It may stimulate production of reactive oxygen species (ROS) which causes oxidative stress in the human body. These products especially salami, sausages etc. include nitrite and nitrate substances to enhance their taste and appearance. ROS are promoted transformation from nitrite/nitrate to $\mathrm{N}$-nitrosa substances which have cancerogenic affects $(5,6,7)$.

Sources of omega 6, unsaturated and trans fatty acids may increase inflammation which is a risk factor for uncontrolled angiogenesis and tumorigenesis. In addition; bile acids are necessary for digestion of fats. The primary bile acids are transformed to secondary ones after digestion and these have cancerogenic affects $(8,9,10)$.

Very hot and/or cold beverages may damage larynx, pharynx, esophagus and stomach tissues. Damaging of these tissues cause inflammation and $\mathrm{N}$-nitrosa production which are risk factors of DNA damage $(11,12)$.

Sugar and sugar containing foods have high glycemic index and load which play role on oxidative stress, 
Table 1. The most cited potentially risky and fighter foods against cancer (Wisemen, 2019; Tandon et al, 2008)

\begin{tabular}{lll}
\hline Potentially risky foods & Fighter foods against cancer \\
\hline - Meat and meat products & $\bullet$ Fresh vegetables and fruits \\
- Fats & $\bullet$ Legumes and seeds \\
- Sugar & - Olive oil \\
- Very hot/cold beverages & - Fish \\
- Alcohol & - Dairy products \\
- Salt and salty foods & $\bullet$ Pro/prebiotics \\
- Contamined foods & \\
- Bad cooking methods & \\
\hline
\end{tabular}

dysbiosis development in microbiota, cell proliferation and differentiation. These effects may enhance cancer cell development so cancer risk $(13,14,15,16)$.

High alcohol consumption is a risk factor of some cancer types because of its ethanol content. Ethanol is a co-cancerogenic substance and it may cause to DNA damage in the cells. In addition; after ingestion or process it may convert to acetaldehyde which has carcinogen effect $(17,18)$.

Molds are mycotoxins and they produce aflatoxins which may be cancerogenic such as aflatoxin $B_{1}$. Corn, peanuts etc. are potentially risky foods for aflatoxin $B_{1}$ which may cause liver cancer (19).

Salt may damage gastrointestinal tissues and cause inflammation which may stimulate cancerogenesis. On the other hand; high amount of salt consumption may decrease apoptosis and increase aerobic glycolysis $(20,21)$.

At last; wrong cooking methods such as frying, grilling, cooking at high temperature etc. may cause production of advanced glycation end products (AGE), polycyclic aromatic hydrocarbons (PAH), heterocyclic amines (HA), N-nitrosa substances and vitamin-mineral losses $(22,23)$.

\section{Fighter foods against cancer}

Some of the foods that fight cancer and their mechanisms of action are shown in Figure 2.

Fresh vegetables, fruits, legumes and seeds may decrease cancer risk because of their fibre, vitamin, mineral and polyphenolic compound contents (4). Dietary fibre, especially soluble fibre, may increase short chain fatty acids (SCFA) production which decrease cancer cell development and increase apoptosis. At the same time, they are food sources of colonic beneficial microorganisms so SCFA improves gastrointestinal microbiota. Insoluble fibre may decrease colonic transit time, thus prevent absorption of cancerogenic substances $(24,25,26)$.

Some vitamins and minerals such as vitamin A, C, E, selenium and zinc etc. and polyphenols may enhance antioxidant capacity in human metabolism. According to their antioxidant affects, they may protect our body from oxidative stress and DNA damage $(3,27,28)$.

Fishes, especially oily fishes, and some seeds such as walnut include omega 3 fatty acids. The best source of omega 9 fatty acids is olive oil. Inflammation is an important risk factor for cancer development. Omega 3 and 9 have roles on anti-inflammatory roads and decrease inflammation in our body. At the same time; omega 3 may increase apoptosis and decrease angiogenesis etc. $(9,29,30)$.

There is a bidirectional relation between dairy products and cancer risk. Dairy products may trigger cancer because of its saturated fatty acids, insulinlike growth factor (IGF) - 1, estrogen and some potential contaminants contents. On the other hand; dairy products contain conjugated linolenic acid, butyrate, lactoferrin, some bioactive peptides and calcium which have potential roles on anticancerogenic mechanisms $(31,32,33)$.

Prebiotics are food sources of beneficial probiotics on human microbiota. They may increase amounts of probiotics and decrease inflammation and cancerogenesis (24). Probiotics have lots of different effects on cancer development such as promoting apoptosis, immuno-modulation, improvement of colonic microbiota and increasing antioxidant capacity etc. $(34,35)$. 


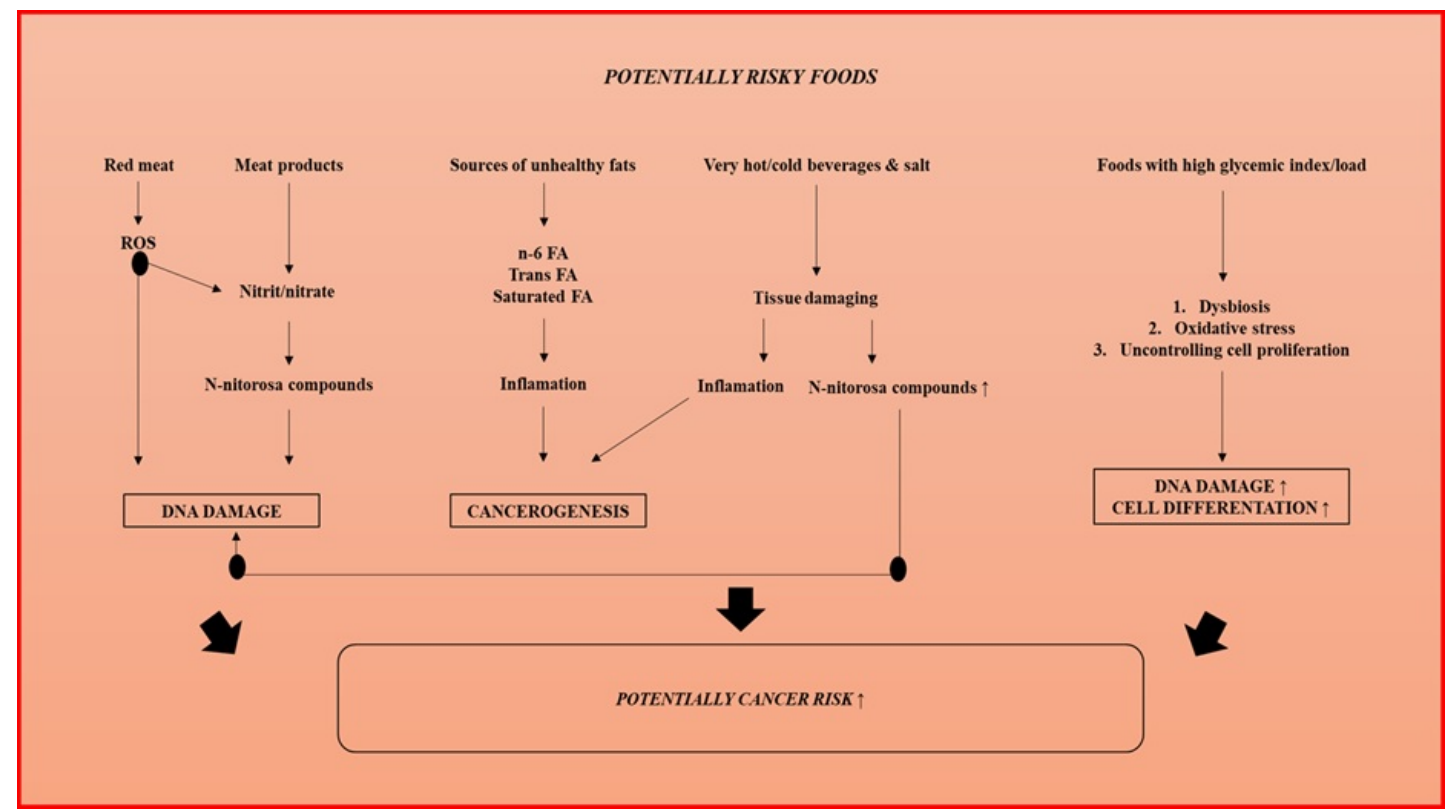

Figure 1. Some potentially risky foods for cancer $(5,6,7,8,9,10,11,12,13,14,15,16)$

Fiolet et al (2018) aimed to determine relation between processed food consumption and cancer. 104,980 people were participated into this study who were more than 18 years old. Processed food consumption (meat products, salty foods, rice etc.) were evaluated from $24-\mathrm{h}$ recalled food recording. All of them were inspected for cancer risk by physicians. They have found relation with processed food consumption and overall cancer risks. In addition; carbohydrates, sodium, nitrite, fats intakes were highest in this group which had cancer risk (36). In a meta-analysis, which aimed to determine importance of vegetables and fruit consumption on breast cancer risk, included ten original articles and 31.210 breast cancer cases. All studies were retrospective, and they were showed; fruits and vegetables intake before diagnosis have positive effects on breast cancer risk (37). Bradbury et al (2020) studied with 475.581 participants from 2006 to 2010 and they recorded their food consumptions. All people who participated in this study, were screened for colorectal cancer diagnosis. Participants who reported consuming an average of $76 \mathrm{~g} /$ day of red and processed meat compared with $21 \mathrm{~g} /$ day had a $20 \%$ higher risk of colorectal cancer. In addition, $19.6 \mathrm{~g} /$ day dietary fibre intake decreased $14 \%$ of colorectal cancer risk. Alcohol was associated with an $8 \%$ higher risk per 10 g/day higher intake. Fish, poultry, cheese, fruit, vegetables, tea and coffee were not associated with colorectal cancer risk (38). In a case control study, which aimed to determine glycemic index and colon cancer relation, there were 1944 participants. They compared food consumptions of groups and reported that; the highest colon cancer risk was found in a group which consumed high glycemic index contained foods (39). In other meta-analysis which included 29 case control and 5 cohort study, Wang et al (2018) reported optimal milk and dairy products consumption (2-3 service in a day) to have positive effects on gastric cancer risk (40). Andrici et al (2015) aimed to determine effects of very hot foods and beverages on esophegeal cancer in their metaanalysis (n: 23 original articles). They have reported that; very hot foods and beverages were associated with esophageal cancer risk (11). At the same time; Chen et al (2015) have found same results in their meta-analysis and supported Andrici et al (12). Kefir is a beverage which include probiotics. In a metaanalysis (n: 11 original articles); researchers have found Kefir to have anti-cancer effects for prevention as well as beneficial effects on cancer treatment (41). In addition; Zamberi et al (2016) have showed antiangionesis, anti-metastatic, anti-inflammatory and anti-cancer effects of Kefir in their cancer stem cell study (42).

\section{SUGGESTIONS}

- To prevent from cancer (3);

- Promote diet diversity,

- Consume fresh vegetables, fruits and legumes,

- Increase consumption of fish and olive oil and decrease meat and sunflower oil, 


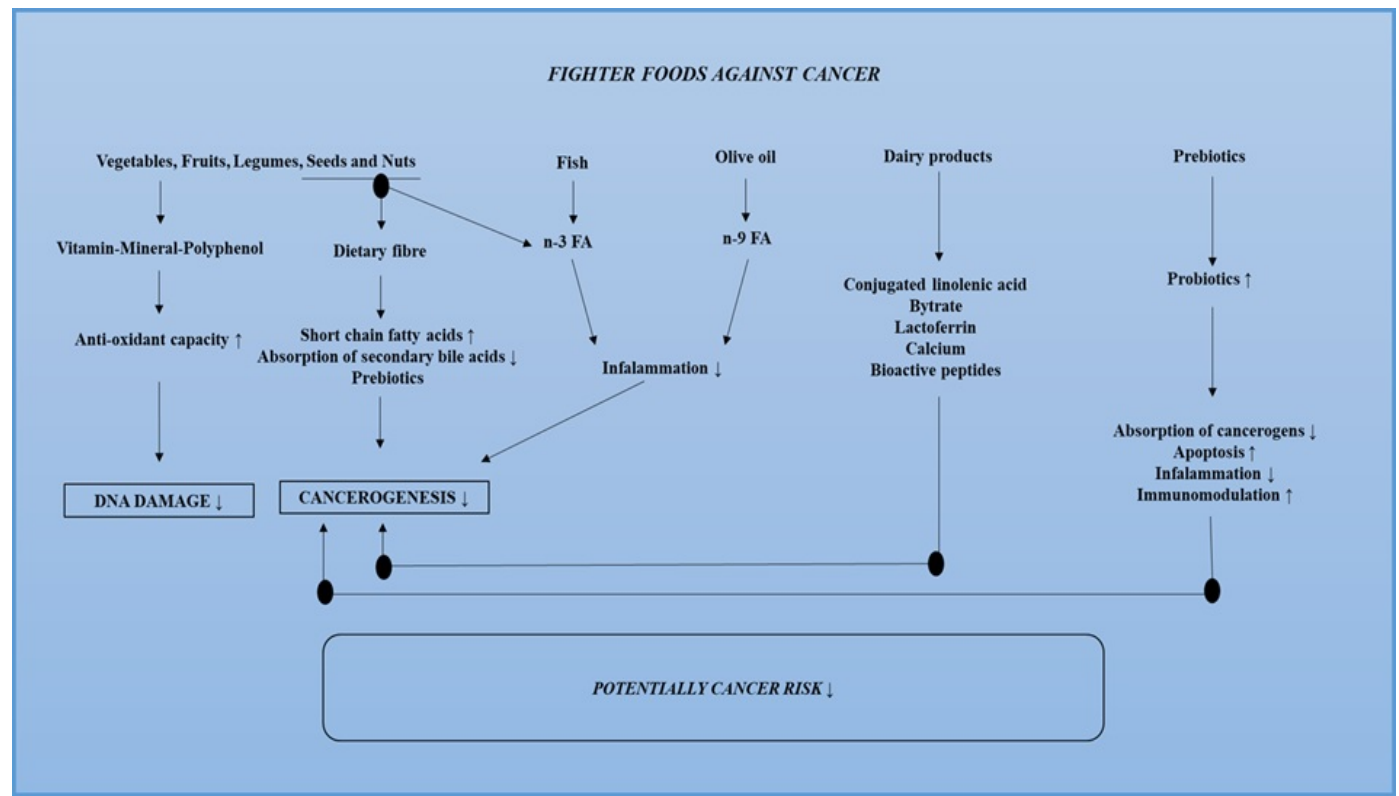

Figure 2. Potentially fighter foods for cancer $(3,9,24,25,26,27,28,29,30,31,32,33,34,35)$

- Decrease consumption of sugar and salt,

- No or moderate alcohol consumption (if you want to drink, prefer red wine),

- Consume milk and dairy products (prefer low fat products).

Accordingly with this up-to-date review we see the area of research and the importance of food intake in relationship with cancer. The delicate balance determines the food to be a friend or foe against cancer.

\section{Peer-review: Externally peer-reviewed.}

\section{REFERENCES}

1. Tyagi N, Sharma GN, Shrivastava B, Chaudhary N, Sahu N. Cancer: An overview. IJRDPL 2017;6(5):2740-2747.

2. Shahab L, McGowan JA, Waller J, Smith SG. Prevalence of beliefs about actual and mythical causes of cancer and their association with sociodemographic and health-related characteristics: Findings from a cross-sectional survey in England. Eur J Cancer 2018;3(1):308-316.

3. Wiseman MJ. Nutrition and cancer: Prevention and survival. Br J Nutr 2019;122(5):481-487.

4. Tyagi N, Sharma GN, Shrivastava B, Chaudhary N, Sahu N. Cancer: An overview. IJRDPL 2017;6(5):2740-2747.

5. Shahab L, McGowan JA, Waller J, Smith SG. Prevalence of beliefs about actual and mythical causes of cancer and their association with sociodemographic and health-related characteristics: Findings from a cross-sectional survey in England. Eur J Cancer 2018;3(1):308-316.

6. Wiseman MJ. Nutrition and cancer: Prevention and survival. Br J Nutr 2019;122(5):481-487.

7. Tandon M, Siddique RA, Arvind Singh NK, Ambwani T, Rai SN. Anti-cancer diet: Reviewing the role of nutrition in cancer prevention. Curr Top Nutraceut R 2008;6(2):1-16.

8. De Cicco P, Catani MV, Gasperi V, Sibilano M, Quaglietta M, Savini I. Nutrition and breast cancer: A literature review on prevention, treatment and recurrence. Nutrients 2019;11(7):1-28.

9. Oostindjer M, Alexander J, Amdam GV, Andersen G, Bryan NS, Chen D, Corpet DE et al. The role of red and processed meat in colorectal cancer development: A perspective. Meat Sci 2014;97(4):583-594.

10. Jin Hur S, Yoon Y, Jo C, Jeong JY, Lee KT. Effect of dietary red meat on colorectal cancer risk - a review. Comp Rev Food Scie and Food Saf 2019;18(6):1812-1824.

11. Goncalves MD, Hopkins BD, Cantley LC. Dietary fat and sugar in promoting cancer development and progression. Annu Rev Cancer Bio 2019;3(2019):255-273.

12. Zanoaga $O$, Jurj $A$, Raduly L, Cojocneanu-Petric $\mathrm{R}$, Fuentes-Mattei E., Wu O, Braicu $\mathrm{C}$ et al. Implications of dietary omega 3 and omega 6 
polyunsaturated fatty acids in breast cancer (Review). Exp Ther Med 2018;15(2):1167-1176.

13. Huerta-Yepez S, Tirado-Rodriguez AB, Hankinson $O$. Role of diets rich in omega 3 and omega 6 in the development of cancer. Bol Med Hosp Infant Mex 2016;73(6):446-456.

14. Andrici J, Phil M, Eslick GD. Hot food and beverage consumption and the risk of esophageal cancer. Am J Prev Med 2015;49(6):952-960.

15. Chen $Y$, Tong $Y$, Yang $C$, Gan $Y$, Sun $H, B i ~ H$, $\mathrm{Cao} S$ et al. Consumption of hot beverages and foods and the risk of esophageal cancer: A metaanalysis of observational studies. BMC Cancer 2015; 15: 1-13.

16. Mills S, Stanton C, Lane JA, Smith GJ, Ross RP. Precision nutrition and the microbiome, part I: Current state of the science. Nutrients 2019;11(4):1-45.

17. Dumitrescu L, Popescu-Olaru I, Cozma L, Tulba D, Hinescu ME, Ceafalan LC, Gherghiceanu M et al. Oxidative stress and the microbiota-gut-brain axis. Oxid Med Cell Longev 2018;1(1):1-12.

18. Vivarelli $S$, Salemi $R$, Candido S, Falzone L, Santagati M, Stefani S, Torino F et al. Gut microbiota and cancer: From pathogenesis to therapy. Cancers 2019;11(1): 1-26.

19. Simpson A, Petnga W, Macaulay VM, WeyerCzernilofsky U, Bogenrieder T. Insulin-like growth factor (IGF) pathway targeting in cancer: Role of IGF axis and oppurtunities for future combination studies. Target Oncol 2017;12(5):571-597.

20. Ratna A, Mandrekar P. Alcohol and cancer: Mechanisms and therapies. Biomolecules 2017;11(1):1-20.

21. Scheideler JK, Klein WMP. Awareness of the link between alcohol consumption and cancer across the world: A review. Cancer Epidomiol Biomarkers Prev 2018;27(4):429-437.

22. Wu F, Stacy SL, Kensler TW. Global risk assessment of aflatoxins in Maize and Peanuts: Are regulatory standards adequately protective? Toxicol Sci 2013;135(1): 251-259.

23. Lin S, Li Y, Leung K, Huang C, Wang X. Salt processed food and gastric cancer in a Chinese population. Asian Pac $\mathrm{J}$ Cancer Prev 2014;15(13):5293-5298.

24. Amara S, Tiriveedhi V. Inflammatory role of high salt level in tumor microenvironment. Int J Oncol 2017;50(5):1471-1481.
25. Bylsma LC, Alexander DD. A review and metaanalysis of prospective studies of red and processed meat, meat cooking methods, heme iron, heterocyclic amines and prostate cancer. Nutr J 2015;14:1-18.

26. Joshi AD, Kim A, Lewinger JP, Ulrich CM, Potter JD, Cotterchio M, Marchand LL et al. Meat intake, cooking methods, dietary carcinogens and colorectal cancer risk: Findings from the Colorectal Cancer Family Registry. Cancer Med 2015;4(6):936-952.

27. Zeng $\mathrm{H}$, Lazarova DL, Bordonaro $\mathrm{M}$. Mechanisms linking dietary fiber, gut microbiota and colon cancer prevention. World J Gastrointest Oncol 2014;6(2):41-51.

28. Navarro SL, Neuhouser ML, Cheng TD, Tinker LF, Shikany JM, Snetselaar L, Martinez JA et al. The interaction between dietary fiber and fat and risk of colorectal cancer in the women's health initiative. Nutrients 2014;8(12):1-16.

29. Ma Y, Hu M, Zhou L, Ling S, Li Y, Kong B, Huang $P$. Dietary fiber intake and risks of proximal and distal colon cancers: A meta-analysis. Medicine 2018;97(36):1-8.

30. Borek C. Dietary antioxidants and human cancer. Integr Cancer Ther 2004;3(4):333-341.

31. Arsova-Sarafinovska Z, Dimovski AJ. Natural antioxidants in cancer prevention. Macedonian Pharmeceutical Bulletin 2013;59(1,2):3-14.

32. Liu J, Ma, DWL. The role of omega 3 polyunsaturated fatty acids in the prevention and treatment of breast cancer. Nutrients 2014;6(11):5184-5223.

33. Borzi AM, Biondi A, Basile F, Luca S. Olive oil effects on colorectal cancer. Nutrients 2018;11(1):1-16.

34. Davoodi H, Esmaeili S, Mortazavian AM. Effects of milk and milk products consumption on cancer: A review. Comp Rev Food Scie and Food Saf 2013;12(3):249-264.

35. Giromini C, Cheli F, Rebucci R, Baldi A. Invited review: Dairy proteins and bioactive peptides: Modeling digestion and the intestinal barrier. J of Dairy Sci 2019;102(2):1-14.

36. Booth GC, Zhang Z, Shannon J, Bobe G, Takata $Y$. Calcium intake and cancer risk: Current evidence and future research directions. Nutrition and Aging 2017;6(2):72-79.

37. Sharma A, Viswanath B, Park Y. Role of probiotics in the management of lung cancer and 
related diseased: An update. J Funct Foods 2018;40(5):625-633.

38. Molska M, Regula J. Potential mechanisms of probiotics action in the prevention and treatment of colorectal cancer. Nutrients 2019;11(10):1-17.

39. Fiolet T, Srour B, Sellem L, Kesse-Guyot E, Alles $B$, Mejean $C$, Deschasaux $M$ et al. Consumption of ultra-processed foods and cancer risk: Results from NutriNet-Sante prospective cohort. BMJ 2018; 14:1-11.

40. He J, Gu Y, Zhang S. Consumption of vegetables and fruits and breast cancer survival: A systematic review and meta-analysis. Sci Rep 2017;7(1):1.10.

41. Bradbury KE, Murphy N, Key TJ. Diet and colorectal cancer in UK Biobank: A prospective study. Int J Epidemiol 2020;49(1):246-258.

42. Huang J, Fang $\mathrm{Y}, \mathrm{Xu} \mathrm{M}$, Luo $\mathrm{H}$, Zhang $\mathrm{N}$, Huang $\mathrm{W}$, Pan $Z$ et al. Carbohydrate, dietary glycaemic index and glycaemic load and colorectal cancer risk: A case-control study in China. $\mathrm{Br} \mathrm{J}$ Nutr 2018;119(8):937-948.

43. Wang S, Zhou M, Ji A, Zhang D, He J. Milk/dairy products consumption and gastric cancer: An update meta-analysis of epidemiological studies. Oncotarget 2018;9(6):7126-7135.

44. Rafie N, Hamedani SG, Ghiasvand R, Miraghajani M. Kefir and cancer: A sytematic review of literatures. Arch Iran Med 2015;18(12):852-857.

45. Zamberi NR, Abu N, Mohamed NE, Nordin N, Keong YS, Beh BK, Zakaria ZAB et al. The antimetastatic and antiangiogenesis effects of Kefir water on murine breast cancer cells. Integr Cancer Ther 2016;15(4):1-14. 